\section{Sunspots and Associated Phenomena}

WALTER G. BowERMAN has an article entitled "Sunspots in Review" in Sky and Telescope of September, which, although containing nothing new on the subject, provides an excellent summary of research in this particular branch. Much still remains to be done on the effects of sunspots, and in some cases results obtained by different investigators are of a contradictory nature. Thus, while some have discovered that the sun radiates more heat to the earth with increase in the number of sunspots, others have found no such correlation, and additional material is necessary before any definite conclusion can be drawn. H. H. Clayton, writing in World Weather, has pointed out that proof of variation in the sun's radiation with sunspot periods is found in the variation of the polar caps of Mars. When the spots are numerous and at the same time a polar cap is tumed towards the sun, it lessens in size. He also states that variations in the light reflected by Jupiter have been found to be associated with sunspot periods. Dr. Stetson, in a letter to Mr. Bowerman, states that evidence from ionospheric investigations reveals an output of solar radiation, especially in the extreme ultra-violet, which is $100-150$ per cent greater at sunspot maximum than at minimum. Huntington, writing in "Earth and Sun", suggests that the planets have an influence on sunspots-akin to trigger action - the energy derived from them being like pressing a button to start an explosion. Once a little eddy is started, the slight movement so generated may be reinforced by stresses due to rapid oooling of the sun's outer layer, or to the sun's varying rate of rotation at different latitudes. Mr. Bowerman admits that there are many pitfalls for the student of solar-terrestrial relations, and one must avoid too hasty generalizations. In different parts of the world relationships to temperatures, pressure, and precipitation are not always the same. For example, the Nile shows a maximum height near sunspot maximum, whereas rivers in temperate regions, such as the Parana in the Argentine, show the reverse. Great care is necessary before formulating definite conclusions.

\section{Industrial Electrical Maintenance}

Is a paper read in London on December 14 before the Institution of Electrical Engineers, J. C. B. Nicol contends that industrial maintenance should be controlled through an organized system. From an analysis of the functions of a maintenance department, he derives the principles underlying good organization and illustrates some of these by examples. There are probably many types of equipment data records in use, and it is believed they are all fundamentally the same if different in detail. These differences must cause considerable trouble to manufacturers when supplying information to various customers, and if standard cards were agreed, manufacturers could easily supply them with their equipment. Manufacturers often supply maintenance instructions and connexion diagrams with their equipment, as well as lists of spare parts. If all such information were provided on standard-size pages, which could be bound into a strong loose-leaf book, it could then be given to workmen with a good chance of survival.

It would be advantageous if a standard code of practice for the maintenance of industrial electrical apparatus were compiled and issued by the British
Standards Institution. Such a code could not make any comprehensive technical recommendations, but it could specify good administrative procedure, which would tend to standardize systems and facilitate the interchange of maintenance engineers. Some standardization on these lines would make the exchange of information between manufacturers and maintenance engineers easier, and would also help installation contractors and consultants to take an interest in maintenance work and its problems.

\section{Plastics in Electrical Industry}

Av article by A. J. Warner (Elec. Comm., 22, No. 1 ; 1944), in reviewing the physical and electrical properties of plastics, discusses the various types of plastic materials available, paying particular attention to their electrical properties, and also examines their physical limitations, since there is no 'all-purpose' plastic available for the variety of conditions encountered. In all cases, a compromise must be made between the electrical properties and the mechanical limitations inherent in the material. In the summary which is provided, which of necessity is incomplete and rather fragmentary, such data are collected and collated as will facilitate an intelligent selection of materials. It cannot be too strongly emphasized, however, that, in the present state of the plastic art, a mere tabulation of physical and electrical properties will not necessarily enable one to choose the right material for any particular application. There still exists and will always exist the need for the exercise of judgment and the use of the accumulated know. ledge of the particular engineer having the problem under consideration.

For the highest degree of electrical performance, where dielectric properties are of paramount importance, the pure hydrocarbons such as polystyrene and polyethylene are the best materials available. Where cheapness, availability, and good overall physical propertiès are required for low-frequency applications, and where only moderate electrical performance is required, the recent developments in the urea formaldehydes should be considered. For large sheets of various thicknesses for panel mounting strips, etc., and where high electric strength, reasonably low moisture absorption, and reasonable electrical properties are required, Grade $X X X P$ laminated plastics are recommended.

\section{Equilibrium Diagrams of Alloys}

Three more "Annotated Equilibrium Diagrams" have been published by the Institute of Metals. No. 2 deals with the copper-tin system, No. 3 with the copper-zine alloys and No. 4 with the copperaluminium. Prepared by Dr. G. V. Raynor, each sheet contains a large-scale diagram in its latest form, some notes upon it, and an extensive bibliography. At the almost nominal price of $6 d$. per sheet, they represent what is probably the best value attainable anywhere in metallurgical literature.

\section{Mineral Deficiencies in Pastures}

Teannrcax Communication No. 15, issued by the Imperial Bureau of Animal Health (Rowett Institute, Aberdeen, 1944. 58.), entitled "Minerals in Pasture, Deficiencies and Excesses in Relation to Animal Health", by Miss F. C. Russell, is a valuable review of this complex subject. The literature surveyed deals with diseases attributed or attributable to 